\title{
The logic of the theoretical and practical products of design research
}

\author{
Matthew W. Easterday, Daniel G. Rees Lewis, and Elizabeth M. Gerber \\ Northwestern University
}

\begin{abstract}
Design research (DR) promises to simultaneously solve practical problems of education and develop theory to guide future interventions. However, educational DR remains paradigmatically underdeveloped, making it difficult to train new researchers, to agree upon what makes a theoretical contribution, and to promise clear outputs to funders - all of which hinders the accumulation of knowledge. To further the paradigmatic development of educational DR we ask: how do we characterise the practical and theoretical products of DR? We propose that DR products are arguments for how people should learn. The theoretical products are design models in the form of blueprints, design arguments, and mockups, as well as principles and frameworks - all of which help designers create practical products to promote learning in the real world. Furthermore, the products of DR precipitate and build upon theoretical contributions from other fields in the natural sciences and ethics. This understanding of the products of DR strengthens the methodology and allows us to better build theory for solving educational problems.
\end{abstract}

\section{Introduction: Issues with the logic of design research}

Societies have designed educational interventions for millennia. Organisational forms for education and design, such as large public school districts or the Bauhaus design workshop developed over a century ago, remain with us today. However, the fields for studying the design of educational interventions in their modern form, such as educational technology and the learning sciences, are relatively recent innovations.

A field designates "research by teams or individuals" that includes a common set of "information, data, techniques, tools, perspectives, concepts, and/or theories ... to advance fundamental understanding or to solve problems" (Committee on Facilitating Interdisciplinary Research, \& Committee on Science, Engineering, and Public Policy, 2004, p. 2). New fields require new methods, which describe a series of phases or steps for transforming something to achieve some purpose (Arthur, 2009, p. 30). For example, the scientific method transforms a set of resources (human, financial, informational, technological, etc.) into an improved understanding of the world. Likewise, educational design research (DR) is a methodology for transforming resources into new theoretical and practical products that help people learn.

Initial descriptions of educational DR are quite recent, beginning with Brown's (1992) description of design experiments followed by special issues on design-based research in Educational Researcher (Kelly, 2003) and the Journal of the Learning Sciences (Barab \& Squire, 2004), as well as several edited volumes and books (Kelly, Lesh, \& Baek, 2008; McKenney \& Reeves, 2013; Plomp \& Nieveen, 2007; van den Akker, 1999; van den Akker, Gravemeijer, McKenney, \& Nieveen, 2006).

Discipline-specific methods take time to develop, so unsurprisingly, after just over a decade of writing about design-based research, we are encouraged to persist: "as promising as the methodology is, much more effort ... is needed to propel the type of education innovation that many of us feel is required” (Anderson \& Shattuck, 2012), and more rigorously define our terms (Dede, 2004; Hoadley 2004; Kelly 2004). While "there remains confusion about how to do DR, with most scholarship on the approach [design research] describing what it is rather than how to do it” (Sandoval, 2014, p. 18), with continued attention, we can develop the methodology further.

Educational DR has gained many adherents because it promises to simultaneously develop theory and interventions for solving educational problems (Barab \& Squire, 2004; Brown 1992; Edelson, 2002; Kelly, 2003; Kelly et al., 2008; Plomp \& Nieveen, 2007; van den Akker, 1999; van den Akker et al., 2006).). Unfortunately, DR remains a low paradigm field relative to fields such as physics. Low paradigm fields are those in which there is less technical consensus about the nature of research, including the goals of research, 
what counts as quality output, the guiding theories, and the methods for conducting the research. Low paradigm fields face greater challenges in training novices, publishing work, and attracting funding - all of which lead to slower production of knowledge (Pfeffer, 1993).

One uncertainty about DR is the nature of its theoretical products. To realise the potential of DR, we must understand the practical and theoretical products it creates so that we can avoid problems of vague, untestable theory, under-conceptualisation, and confusing terminology, that hinder the production of useful knowledge.

Novice (and experienced) design researchers are often encouraged to make specific and testable theoretical design claims (Herrington, McKenney, Reeves, \& Oliver, 2007), yet it is difficult to find descriptions of what precisely constitutes theory in DR. For example, DR proponents (diSessa \& Cobb, 2004) describe a number of types of theory that do not seem to generate testable design claims, including grand theories, such as Piaget's theory of intellectual development, that are not intended to inform design; orienting frameworks, such as constructivist theory, that do not "provide strong constraints or detailed prescriptions" (p. 81) for design; and frameworks for action, such as constructionism, that "provide some focus and direction" but "fail to serve the role of theory" because they are too vague or complex to falsify (p. 82). Dede (2004, p. 108) describes the problem similarly:

I would be hesitant to hire an engineer whose "design" consisted of a statement that the structure built would be based on the principles of Newton's Laws, gravity and friction. Such underspecification can easily lead to situations in which [design based research] presents unfalsifiable propositions, with failures always attributable to defects in implementation rather than flaws in the theory-based design itself.

Under-conceptualisation, or a lack of theory, poses another problem for DR studies. For example, Dede (2004) criticises over-methodologised studies that compensate for a lack of theory by applying an overabundance of methods in which "only the first five percent or so of the data collected were needed to induce the findings," without a theory to guide data collection, "everything that moved within a 15-foot radius of the phenomenon in question was repeatedly interviewed, videotaped, surveyed, and so forth-and this elephantine effort resulted in the birth of mouse-like insights in their contribution to educational knowledge" (p. 107). Under-theorised studies risk being over-methodologised, inducing significant effort without producing useful knowledge for the educational research community.

Furthermore, DR methodology could benefit from the use of consistent terminology. Terms such as theory, framework, principles, and laws are used inconsistently across authors (Giere, 2006, p. 69; Kelly, 2004) and sometimes even within a single article. Inconsistent terminology may reflect a problem not with DR per se so much as a lack of consensus amongst researchers and philosophers about what constitutes theory. While we cannot fully resolve that debate here, we can outline an approach to understanding theory that allows us to describe the practical and theoretical products of DR.

\section{DR process}

The DR process consists of 7 interleaved phases (Easterday, Rees Lewis, \& Gerber, 2014) in which the design researcher focuses the project, understands the situation, defines the problem, conceives a solution, builds the solution, tests the solution, and presents to stakeholders (Figure 1). Table 1 describes the general nature of each phase and how it is modified for research. 


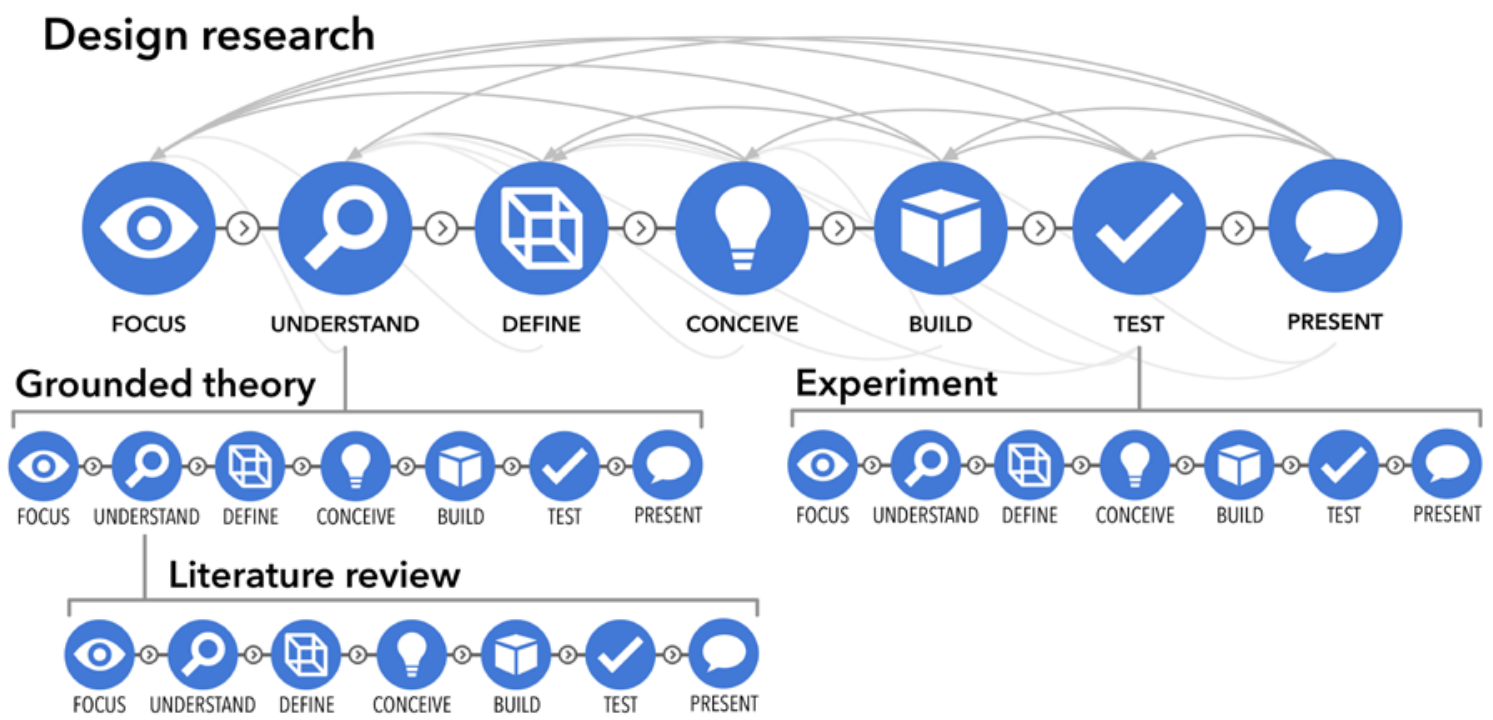

Figure 1. The DR process consists of 7 interleaved phases that may recursively nest additional research processes.

Table 1

The design and design research processes consist of 7 interleaved phases

\begin{tabular}{|c|c|c|}
\hline Phase & Description/Purpose & Additional concerns in research \\
\hline Focus & $\begin{array}{l}\text { Bound the scope of the project / to ensure } \\
\text { that the project pursues an important goal } \\
\text { that can be achieved with current resources }\end{array}$ & $\begin{array}{l}\text { Include the research community as } \\
\text { stakeholder }\end{array}$ \\
\hline Understand & $\begin{array}{l}\text { Study learners, domains, contexts, } \\
\text { stakeholder needs and existing solutions / to } \\
\text { understand the nature and causes of the } \\
\text { current situation }\end{array}$ & $\begin{array}{l}\text { Use the methods of design as well as } \\
\text { those of other research methods in } \\
\text { education }\end{array}$ \\
\hline Define & $\begin{array}{l}\text { Define the problem, including the learning } \\
\text { goals and assessments, and constraints / to } \\
\text { convert indeterminate situation into a } \\
\text { problem that can be solved }\end{array}$ & Define research question \\
\hline Conceive & $\begin{array}{l}\text { Sketch a plan for the solution / to allow } \\
\text { designers to test the design against their own } \\
\text { knowledge and theory; identify problems } \\
\text { and improved solutions before committing } \\
\text { to implementation }\end{array}$ & Articulate novel design arguments \\
\hline Build & $\begin{array}{l}\text { Instantiate the solution as a usable prototype } \\
\text { / to produce an effect }\end{array}$ & $\begin{array}{l}\text { May sacrifice features unnecessary for } \\
\text { instantiating theoretical design } \\
\text { arguments }\end{array}$ \\
\hline Test & $\begin{array}{l}\text { Evaluate the efficacy of the solution / to } \\
\text { determine the success of the design and } \\
\text { validity of the theoretical propositions. }\end{array}$ & $\begin{array}{l}\text { Have greater obligation to provide } \\
\text { evidence for the effectiveness of the } \\
\text { theory / product }\end{array}$ \\
\hline Present & $\begin{array}{l}\text { Communicate to key stakeholders why the } \\
\text { design will better solve a problem that } \\
\text { addresses their interests / to ensure } \\
\text { appropriate support for the project }\end{array}$ & $\begin{array}{l}\text { Create presentations, research papers } \\
\text { and grant proposals for the academic } \\
\text { community }\end{array}$ \\
\hline
\end{tabular}


We can thus formally define educational DR as follows:

Educational design research is a meta-methodology used by design researchers to create practical products and theories through a design process of focusing, understanding, defining, conceiving, building, testing and presenting, that recursively nests other research processes in a state-dependent search, to better solve practical problems of human learning.

This formal definition identifies how the DR process deploys other research methods during each phase of design in a nested manner (Figure 1). For example, during the understand phase a design researcher might collect field data and undertake a grounded theory analysis to better understand learners in context. Or in an early test phase, a DR might collect qualitative data about how the intervention is used, and in a later test phase, conduct a controlled, randomised field trial to validate the causal effect of the intervention. This nesting of other scientific methods within a design process that creates novel practical products explains the shape-shifting nature of DR and how it integrates theory and practice. This is why DR is sometimes described as a meta-methodology (Bannan, 2007, p. 120) that integrates other research methods into the design process to do its work.

\section{Purpose: What are the products of DR?}

While the formal definition answers questions about the relation of science, design, and practice, and how DR produces theoretical and practical contributions, questions still remain. What is the nature of the practical and theoretical products of DR? Drawing upon existing literature in learning sciences, design, and philosophy of science, we expand the formal definition, focusing on the products of DR by asking:

(1) What are DR products for?

(2) What form do the practical products of DR take?

(3) What form do the theoretical products of DR take?

(4) How are the theoretical products of DR related to the theoretical products in other fields?

\section{Question 1. What are DR products for?}

Rhetorical theories of design define it as a form of argumentation. One can think of argumentation narrowly as the use of language to persuade an audience to adopt an idea, or more generally as an intervention to change an audience in some desired way. In this general sense, designers create products that interact with people to achieve a desired purpose (Buchanan, 2001a, pp. 14-17; 2001b, pp. 195-197), in other words, "products [are] arguments about how we should lead our lives” (Buchanan, 2001b, p. 194).

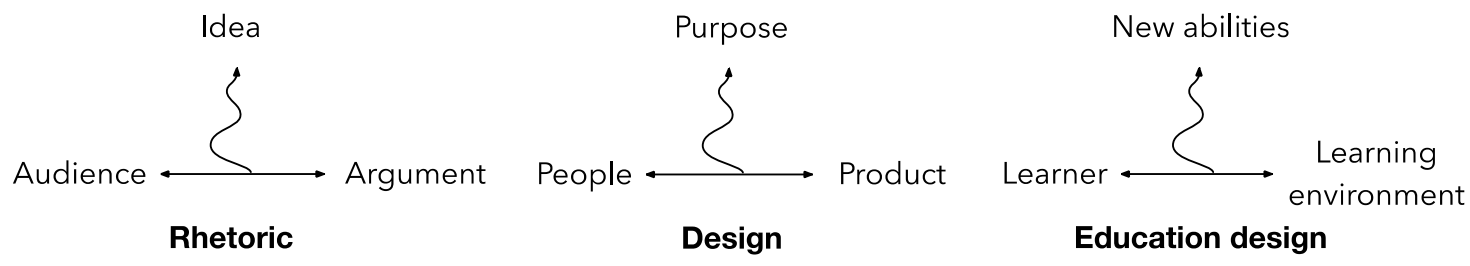

Figure 2. Educational design can be thought of as a form of design which can be thought of as a form of rhetoric.

Applied to learning, this means that educational interventions are arguments about how we should learn. Educational designers create interventions that interact with learners so that they develop new abilities in some domain (see Figure 2). Just as the audience for a spoken argument may respond with counterarguments, the learners in an educational intervention may respond by adapting or rejecting the offered design. Designers take different approaches to promote desired interactions such as creating flexible products that can be more easily customised; conducting participatory design that includes users on the design team (Simonsen \& Robertson, 2013); and following agile design processes with frequent build-test cycles (on the order of weeks, days, or even minutes, see Sutherland, 2014). 
Educational researchers call the interactions between learners, interventions and the domain to be learned instructional dynamics:

Education is the deliberate activity of helping learners to develop understanding and skills. ... it is typically associated with schools, where it consists of interactions among teachers, students, and content, in the various environments of schools (Cohen, Raudenbush, \& Ball, 2003). ... We consider these multiple interactions, which we call the instructional dynamic, to be the defining feature of education. (Ball \& Forzani, 2007, p. 530).

Educational designers and design researchers create arguments for how people learn in the form of practical products called interventions, which if novel are called prototypes. Design researchers also develop explicit, formalised theory that guides the design of future prototypes. This theory describes how interventions lead to a specific outcome in a certain context. Whereas the natural sciences seek to explain the physical world, DR seeks to explain how interventions interact with the world to achieve a desired effect. Many disciplines are defined by the study of how we might influence the world through designed interventions, including design, engineering, educational research (Ball \& Forzani, 2007), sciences of the artificial, that is, of designed artifacts (Simon, 1996), and educational technology:

Educational technology is first and foremost a design field, and thus design knowledge is the primary type of knowledge sought in our field ... the paramount research goal should be solving teaching, learning, and performance problems, and deriving design principles that can inform future development and implementation decisions. (Reeves, 2006, p. 61).

Thus, educational interventions are arguments for how we should learn. The goal of the educational DR is to develop new arguments that can guide the creation of practical products. This requires understanding the structure of educational interventions and how they interact with learners in context to develop new abilities, which in turn requires building novel practical products.

\section{Question 2. What form do the practical products of DR take?}

Fields such as the learning sciences are what Stokes (1997) described as use-inspired basic research, that is, they seek both fundamental understanding and considerations of use (Hannon \& Al-Mahmood, 2014; Phillips, Kennedy, \& McNaught, 2012; Schoenfeld, 2006). These fields do not just seek to understand the process of learning and the structure of interventions, but also to create practical products (such as curriculum, software, policies) that can be deployed in the real world to promote deeper and more efficient learning. What form then do these practical products take?

\section{Practical design products: prototypes}

Once we see the purpose of education research as guiding the design of interventions that promote learning, the impetus for DR methodology becomes clear. Educators have always designed interventions to promote learning - DR recognises that fact and brings the design of interventions under the purview of research, including both the design of novel interventions as well as theory to guide the design of future interventions. As a method, DR (in all its forms, including engineering the sciences of the artificial) is unique in that its object of study is previously non-existent interventions that achieve some purpose.

To develop theory, design researchers create prototypes - novel interventions instantiated in the real world. Educational designers and researchers are interested in a wide variety of prototypes ranging from curriculum to government policies, instructional techniques, interactive software, learner communities, schools, museums, and so on. What form do these prototypes take? 


\section{Rhetorical balance of prototypes}

In rhetoric, arguments balance logos, pathos, and ethos to appeal to an audience (Aristotle, 4th century $\mathrm{BC} / 2007)$. When we view design as a form of rhetoric that makes arguments about how we should live, then we see well-designed products as finding a rhetorical balance between usefulness, usability, and desirability (Figure 3). For example, an iPod is useful in that it allows one to enjoy music; it is usable, in that it "fit[s] the hand and mind of the person who uses it," and desirable if it "leads someone to identify with it and want it to be part of his or her life.” (Buchanan, 2001b, p. 16). The balance between the three should be tailored to a specific audience. For example, a technical, utilitarian audience might value usefulness over other concerns, whereas consumer products may emphasise desirability. Furthermore, designers continuously create new products and audience segments by altering the rhetorical balance of a particular product. For example, low-cost air carriers offer more spartan service for an audience segment that values lower price over comfort, whereas Apple's iPod found a large audience willing to pay a premium for an MP3 player that elevated desirability and usability (by providing a better designed user experience, the addition of iTunes service, and music industry partnerships).

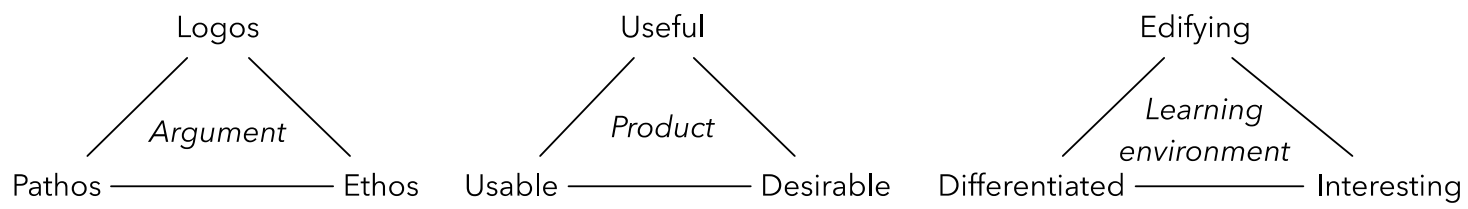

Figure 3. Prototypes in rhetoric, design, and education strive for a rhetorical balance appropriate to their audience.

Interventions must also find an effective rhetorical balance to help learners develop new abilities. That is, the interventions must edify, by substantially engaging learners in the domain (logos/useful), which requires differentiating or tailoring the environment for particular learners (pathos/useable) and establishing the credibility of the intervention by offering an experience of interest to learners (ethos/desirable). Poorly designed interventions can fail by focusing too much on developing abilities, such as a boot camp or classroom that is overly challenging or dry. An intervention can fail by focusing too much on ethos, such as video with high production values or a charismatic lecturer that provides little substance. An intervention can fail by focusing too much on learners, such as a game that is entertaining but doesn’t teach new skills.

\section{Educational design medium: orders of prototypes}

Educational prototypes such as lesson plans, software, or policies, are implemented in a particular medium. The particular medium will vary depending on the educational problem (or more precisely, on the prototype designed to solve the problem). Design theorists such as Buchanan (2001b) describe four different orders of design, after McKeon's (1998) orders of symbols, things, action, and thought. Applied to educational interventions, these are the orders of:

- $\quad$ signs and symbols, which concerns the creation of signs and symbols, such as multimedia, animation, external representations and text;

- $\quad$ things, which refers to physical objects, such as tangible tabletops or library spaces;

- $\quad$ actions, which refers to interaction design and service design, including the design of curriculum, educational games, or tutoring programs; and

- $\quad$ thought, which refers to systems including the design of schools and policy.

The four orders are not meant to be a rigid set of categories for classifying educational interventions, but rather a set of placements that can be used to reframe educational problems to generate new insights and solutions. For example, new approaches to DR such as Design-Based Implementation Research (Penuel, Fishman, Haugan Cheng, \& Sabelli, 2011) represent a reframing of the problem of DR to focus on systems and organisations - essentially changing the problem from one of classroom interaction (action) to one of systems (thought). In changing the order of design, we change the focus of the problem and the medium of the prototype. 


\section{Why prototypes alone are not theory}

Although not identical to the view we take here, some argue that sufficiently novel, relevant, extensible, and rigorously designed prototypes are themselves theoretical contributions (Zimmerman, Forlizzi, \& Evenson, 2007, p. 493). There are many reasons why one might consider prototypes to be theory. Prototypes provide a powerful means of guiding future design through analogy and adaptation. Prototypes provide a proof of concept - theory by itself does not produce learning nor can one develop design theory in the absence of any prototypes and interventions. Furthermore, whereas theory is often vague and incomplete, a successful prototype provides suitable answers to the entire set of design decisions that must be made to address a design problem. Some authors thus argue that prototypes are a kind of living theory, and we should not underestimate their theoretical import. Prototypes are often necessary for making a theoretical contribution in the same way that data is necessary for making a theoretical contribution. However, we believe that while prototypes, like data, provide important support for a claim, prototypes alone are not sufficient for a theoretical contribution.

The power of a prototype to produce an effect and serve as the basis for theory stems from the fact that it properly addresses the questions raised by a particular design problem. However, the completeness of a prototype also undermines the prototype's usefulness for guiding design in new situations, for several reasons. First, the prototype alone does not specify the desired effect on the learner or the nature of the interactions between the prototype and the learner that lead to that desired effect. Second, the prototype alone does not distinguish between what aspects of the prototype are necessary and which are contingent, what is deep structure and what is superficial. So in addition to the prototype, we also require a description of the principle by which it works (Arthur, 2009, p. 33), that is, a design theory that provides our best, explicit argument for why the design succeeds and how this success can be replicated in new settings.

However, if a prototype alone is insufficient to make a theoretical contribution, a theory without a prototype lacks a proof of concept. The prototype shows that a theory can be operationalised. The prototype does not provide evidence of feasibility or of the desired effect on learning, (or a "proof" in the mathematical sense). But demonstrating that theory can be operationalised is important because it cannot always be taken for granted, especially in the case of a complex intervention. For example, building a prototype of an intelligent tutor for policy argumentation that can diagnose and provide responses to learner reasoning shows it's possible to operationalise step-level, artificial intelligence feedback on policy arguments (Easterday, Aleven, Scheines, \& Carver, 2011), even if it does not show that such a system can be feasibly implemented in schools or produce the desired effect on learning. In these cases, demonstrating that the theory can be implemented may itself be a significant contribution.

Researchers do not hold a monopoly on theoretical insight - professional designers must recognise the guiding principle of a design to do their work. DR adds to design practice by making the principle explicit, showing its contribution to the literature and sharing it publicly.

Of course, this raises the question, what form then does this theory take?

\section{Question 3. What form do the theoretical products of DR take?}

If prototypes alone are not sufficient for making a theoretical contribution, then we must specify what other elements are needed. When discussing theory, researchers often discuss frameworks, principles, and models, although these terms are often defined vaguely or in contradictory ways. What are these elements and what theoretical role do they play in DR?

\section{Frameworks provide theoretical structure}

The term framework has been used in many different ways, so here we use the following definition:

Frameworks identify the elements and general relationships among these elements that one needs to consider for ... analysis and they organize diagnostic and prescriptive inquiry. They provide a general set of variables that can be used to analyze all types of ... arrangements. 
Frameworks provide a metatheoretical language that can be used to compare theories. They attempt to identify the universal elements that any theory relevant to the same kind of phenomena needs to include. (Ostrom, 2011, p. 8)

A framework specifies the abstract entities and the relationships between entities that theories make claims about. For example, Ball and Forzani’s (2007) instructional dynamics and Buchanan's (2001b) formal definition of design are both frameworks that suggest that educational DR concerns the interactions between learners and interventions to develop new abilities in a domain. These frameworks focus the educational researcher's attention on constructs of, and interactions between, learners, teachers, environment, and content. Frameworks specify the grammar from which principles are constructed. Their theoretical purpose is to direct attention to the constructs important for building more specific models and for defining the objects of design principles.

However, because frameworks serve to define entities, they do not provide specific guidance for design or make testable claims.

\section{Principles provide theoretical components}

Design principles are typically presented as general causal statements that serve as vehicles for making empirical claims (Giere, 2006, pp. 61-62; van Merriënboer \& Kirschner, 2007, p. 146). In educational DR, these principles typically describe how an intervention leads to a desired learning outcome or, if formulated as a principle of learning, how learner characteristics and behaviours (that can be intervened upon) affect learning outcomes.

For example, consider the following principles, most of which are formulated as principles of learning, but each of which is associated with specific interventions (Ambrose, Bridges, DiPietro, Lovett, \& Norman, 2010, pp. 1-9):

- $\quad$ Students' motivation determines, directs, and sustains what they do to learn.

- To develop mastery, students must acquire component skills, practise integrating them, and know when to apply what they have learned.

- Goal-directed practice coupled with targeted feedback enhances the quality of students' learning.

Design principles provide generalisable components for constructing design arguments, but are usually too general to be directly tested by a design, both because they rarely specify the conditions in which they apply, and because additional work must be done to map these principles onto the world and onto specific prototypes (Giere, 2006, pp. 59-95). For example, if a particular prototype that supports "goal-directed practice coupled with targeted feedback" fails to produce learning, one would not necessarily conclude that "goal-directed practice with targeted feedback does not work," so the theoretical status of the principle is "not really at stake” (diSessa \& Cobb, 2004, p. 82). This is why this kind of statement is rightly criticised as being unfalsifiable (Dede, 2004; diSessa \& Cobb, 2004).

However, the theoretical function of principles is to provide a basis for constructing models that can be tested (Giere, 2006, pp. 59-95. How is this theoretical work done?

\section{Models provide the basis for theoretical work}

Researchers build theory by creating representations of the world for different purposes (Giere, 2006, pp. 59-95), such as explanation, prediction, and intervention. This representational activity occurs through the creation of models, including physical models, analog models, scale models, and mathematical models. Scientists interpret representational models to make claims that are identified with features of the real world, or rather models of data from the real world. By interpreting and identifying representational models, scientists make specific hypotheses and generalisations that can be tested and used to assess the fit of the model with the world and the usefulness of the model for achieving the scientists' purpose (Figure 4). 


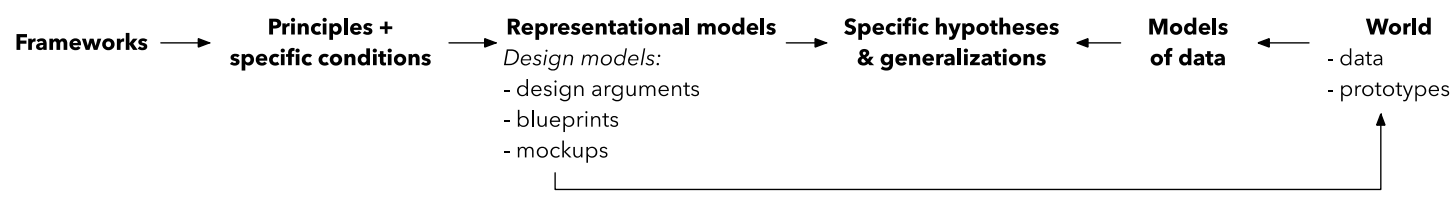

Figure 4. Principles are templates for representational models that create testable hypotheses (after Giere, 2006, p. 61)

What sorts of representational design models do design researchers construct to represent how prototypes promote learning? From general to specific, these models include design arguments, blueprints, and mockups.

\section{Design arguments}

Design arguments are a type of design model that describe the features of a design necessary to promote a desired learning effect in a given context. One form of the design argument (van den Akker, 1999) is described by Figure 5, which references the design of an online platform designed to connect learners with expert professionals (Rees Lewis, Harburg, Gerber, \& Easterday, 2015). A design argument describes the goals of the design, whom it serves, in what context, and the necessary features the design should include. The design argument also describes the procedural focus, that is, not just the features that a new design should have, but also the necessary means by which a designer should go about creating a new product to ensure its success. For example, if a designer is creating a journalism curriculum for immigrant learners that leverages their cultural resources, then the designer might need to survey the learners to identify these cultural resources in order to design the curriculum for a new setting. Finally, the design argument describes the reasons why the intervention should be designed this way, connecting to existing design principles and learning theories.

If you want to design a <computer-supported help-seeking> intervention for the purpose <of increasing industrial design abilities $>$ in the context <of an informal, extracurricular, university design clubs>, then you are best advised to give that intervention the characteristics <access to professional mentors that can provide feedback, direct instruction of help-seeking strategies, establishing routines to surface problems and online tools to track help requests $>$ (substantive emphasis), and to do that via procedures <selecting mentors with expertise on students' projects> (procedural emphasis), because of arguments $<$ from principles of help seeking and feedback from learning sciences, surfacing problems from organizational sciences, and designing online communities from human-computer interaction>.

Figure 5. A design argument (van den Akker, 1999) describes how the design achieves its purpose, for whom and under what conditions, at the most abstract level.

There are also other forms of design arguments. For example, conjecture maps (Sandoval, 2004, 2014) serve a similar function by graphically describing how high level conjectures map to an instantiated product, and lead to specific outcomes through different mediating processes. Impact maps graphically describes how features of the practical product promote different behaviors among different participants to achieve specific learning goals (Figure 6). Collins (1992) used causal models with independent variables to describe the features of the design (substantive focus of the design argument) and how they interact to affect the desired outcomes. 


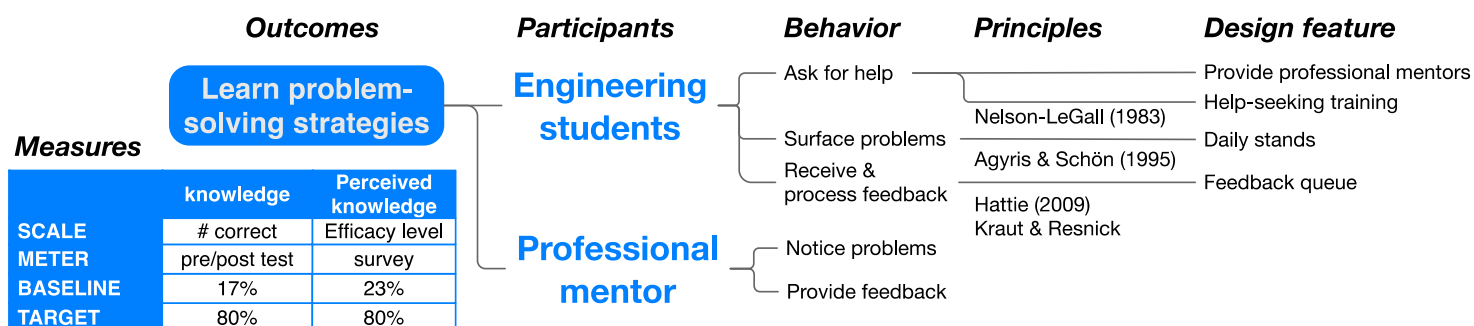

Figure 6. Design arguments can be represented graphically as impact maps such as in this example for engineering students learning problem-solving strategies.

Design arguments function as very abstract design models that can be used to map principles to specific conditions and provide templates for more specific blueprints. What design arguments gain in generalisability, they lose in operationalisability - by abstracting away details, it becomes difficult to say whether the success or failure of a particular prototype supports or undermines a corresponding design argument. Yet by describing the context in which a set of design principles applies, design arguments still function as design models that can be used to generate hypotheses and generalisations about the world (or more specific design models that generate more specific hypotheses). Furthermore, because they are simplified representations of blueprints, design arguments can be used to quickly communicate the core idea of a design.

\section{Design blueprints}

Blueprints are the design models that do the most theoretical work. Blueprints (Figure 7) define the important features of a design and the learning outcomes it supports. Blueprints are thus both general enough to abstract away contingent aspects of the design, and specific enough to be mapped to the real world and tested. The usefulness of blueprints lies in their ability to help designers and design researchers create new interventions with the desired learning outcomes.

Blueprints can take a variety of forms such as E2ML diagrams (educational environment modelling language, a language similar to visual software diagrams for instructional design; Botturi 2006), service blueprints (Bitner, Ostrom, \& Morgan, 2008; Shostack 1987), or any other form that sufficiently describes the structure of the intervention and the way that learners and interventions interact to promote learning. Blueprints can also take the form of design patterns, a concept borrowed from software engineering and architecture (Alexander, Ishikawa, \& Silverstein, 1977; Gamma, Helm, Johnson, \& Vlissides, 1995), which also describe similar features of design arguments including the intent (goal), applicability (context), structure (substantive focus) and examples (the equivalent of artefacts in software). 


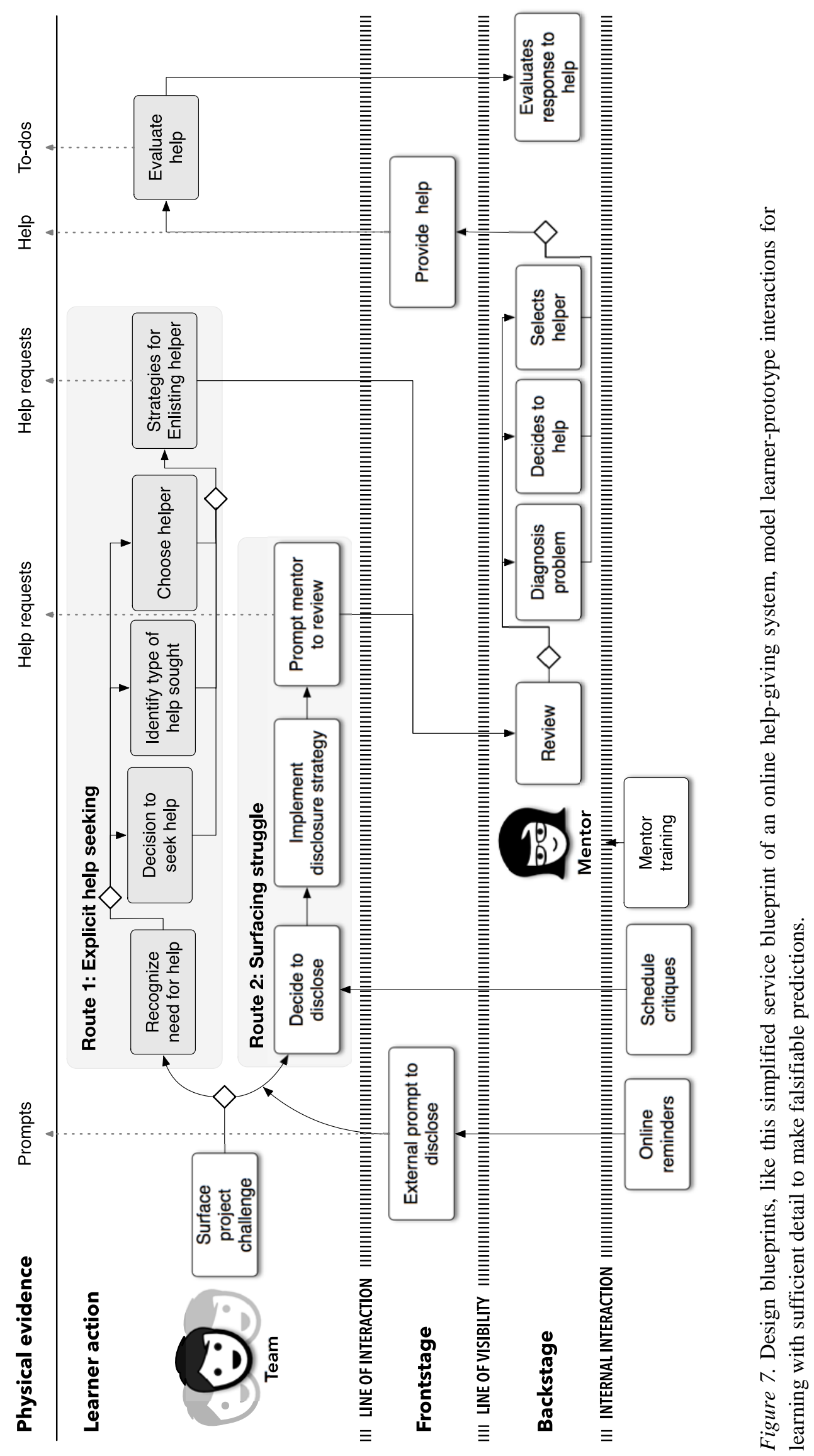




\section{Design mockups}

Mockups are representational design models that allow designers to create and test partial functionality of preliminary concepts before constructing a full prototype. Mockups include paper prototypes, design sketches, and preliminary pilot units. Mockups allow design teams to explore and evaluate core ideas through partial, quickly constructed low-fidelity artifacts, which helps identify and avoid obvious problems before wasting substantial effort implementing a flawed prototype. As such, mockups are essential models for designers.

However, at the other extreme of design arguments, mockups are overly detailed with respect to theory because they typically include a host of contingent features that may be more or less relevant to the overall "theory of the thing" but must still be thought through as a guide for developing prototypes. Mockups include details about the prototype needed to make the design argument (i.e., contingent features), but does not fully materialise the design argument into a prototype that can be used to promote learning in the real world.

\section{Models, principles and frameworks}

Design models, such as design arguments, blueprints, and mockups allow researchers to represent prototypes and their interactions with learners to develop new abilities. Researchers can use these models to generate specific hypotheses that can be compared to data (or rather models of data) to some desired level of fit. For example, the blueprint of the help-seeking intervention in Figure 7 suggests many testable hypotheses, such as that prompts (guiding questions about learner work) will cause learners to make their thinking visible, or that surfacing problems to mentors will prompt them to offer useful help. Researchers use design models to do most of the theoretical work in DR. Frameworks and principles are important for guiding researchers' attention and providing the components from which design models are constructed. However, it is perhaps unwarranted to view principles and frameworks as the primary vehicle of theoretical contributions - design models (design arguments, blueprints, and mockups) are more specific and useful for explaining, analysing, and developing educational interventions, and can thus be created to address the common criticisms of design theory as being under-conceptualised or unfalsifiable.

\section{Question 4. How are the theoretical products of design research related to theoretical products in other fields?}

\section{Theoretical products from other methodologies}

As a methodology, DR is unique in that its objects of study are previously non-existent interventions to achieve some purpose. DR creates novel practical products as part of the research process and produces design models as its theoretical contribution. However, DR also requires and precipitates other kinds of theoretical contributions to produce design arguments. In other words, there are other theoretical contributions required by DR that may be produced during a DR project but that do not strictly require DR to produce.

Table 2 lists the various forms of theoretical contributions required by DR projects to produce design arguments. This includes contributions of philosophy or ethics and contributions of science (problem definition, expertise, and learner challenges):

- $\quad$ Ethics. Theoretical contributions of ethics argue for why learners should acquire a given competence. These are ultimately philosophical or political arguments as opposed to scientific arguments, but are necessary for establishing the importance of the design problem.

- Problem definition. Theoretical contributions of problem definition, define the domain. For well-established domains, one can define problems by interviewing or observing experts, but in some cases, researchers may be attempting to promote learning in a domain that is in the process of being created. 
- Expertise. Theoretical contributions of expertise involve identifying the knowledge, skills, dispositions, tools, environments, etc., required for competency in the domain. Educational designers often use different forms of task analysis to study expertise. This is congruent with Edelson's type II domain theory - an outcomes theory (Edelson, 2002, p. 113; 2006, p. 101) because the model of expertise describes competencies the designers intend for learners to acquire, that is, the intended learning outcome. An outcomes theory should also include the unintended outcomes of a design, which would also be described by the design argument.

- Learner challenges. Theoretical contributions of learner challenges define the difficulties learners face in acquiring some ability relative to the model of expertise, which might result from a lack of, or conflicting, learners' abilities/resources or be alleviated by leveraging learners' abilities/resources. This is congruent with Edelson's type I domain theory - a context theory (Edelson, 2006, p. 101; 2002, p. 113; The Design-Based Research Collective, 2003, p. 8), which also includes the next kind of contribution.

- Context. Theoretical contributions of context define the characteristics of the setting in which the prototype will operate. These contributions describe aspects of the context that impact how learning and the resources and constraints of the interventions, including the learners and instructors involved in the environment, facilities, materials, equipment, institutions, organisations, and communities, (Hattie, 2009; Lee, 2003; Tessmer \& Harris, 1992). This kind of contribution provides "a deeper understanding of the contexts of ... education, particularly how these contexts arrangements produce patterns of educational outcomes” (Penuel \& Fishman, 2012, p. 282).

- Design arguments. Theoretical contributions of design arguments rely on these other kinds of contributions. In order to produce an important, novel design argument, the design has to address an important domain (ethical contribution) and produce a useful learning outcome (expertise contribution) that learners have difficulty achieving (learner challenges) in a given context (context theory).

Table 2

Types of research contributions

\begin{tabular}{|c|c|c|}
\hline Field & Form of principle & (Simplified) Example \\
\hline \multicolumn{3}{|c|}{ Philosophy } \\
\hline Ethics & $\begin{array}{l}<\text { Domain } \mathrm{X}>\text { is important for } \\
<\text { learners } \mathrm{Y}>\text { because }<\text { reasons } \mathrm{A}, \mathrm{B} \text {, } \\
\mathrm{C}>\text {. }\end{array}$ & $\begin{array}{l}<\text { Policy analysis }>\text { is an important discipline } \\
\text { for }<\text { all citizens }>\text { because }<\text { it prepares them } \\
\text { to engage in the public discourse upon which } \\
\text { our democracy depends }>\text {. }\end{array}$ \\
\hline
\end{tabular}

\begin{tabular}{|c|c|}
\hline \multicolumn{2}{|c|}{ Natural sciences } \\
\hline $\begin{array}{l}\text { Domain } \\
\text { definition }\end{array}$ & $\begin{array}{l}\text { Expertise in }<\text { domain } \mathrm{X}>\text { involves } \\
<\text { tasks } \mathrm{A}, \mathrm{B}, \mathrm{C}>\text {. }\end{array}$ \\
\hline Expertise & $\begin{array}{l}\text { Experts competent at }<\text { task } \mathrm{X}>\text { use } \\
<\text { knowledge } \mathrm{A} \text {, skills, } \mathrm{B} \text {, dispositions } \\
\mathrm{C} \text {, with tools } \mathrm{D} \text {, with resources/people } \\
\mathrm{E}>\text { in }<\text { context } \mathrm{Z}>\text { and }<\text { standard of } \\
\text { success } \mathrm{Y}>\text {. }\end{array}$ \\
\hline
\end{tabular}

Learner $\quad<$ Learners $\mathrm{Y}>$ have difficulty doing challenges $\quad<$ task A $>$ because they <lack knowledge A, skills B, dispositions $\mathrm{C}$, tools $\mathrm{D}$, and resources $\mathrm{E}>$, $<$ have misconceptions $\mathrm{F}>$, although they $<$ do have productive capabilities including knowledge G, skills H, dispositions I, tools $\mathrm{J}$, and resources $\mathrm{K}>$.
Expertise in <policy analysis $>$ involves $<$ writing policy briefs $>$.

Experts competent at <writing policy briefs $>$ use <the skills of: identifying a policy problem, studying its causes, defining desired outcomes, finding options and testing the feasibility of those options $>$ in $<$ a representative democracy $>$ and $<$ succeed by developing feasible policies that will better achieve desired outcomes>.

Undergraduates have difficulty < analyzing policy briefs $>$ because they $<$ have trouble understanding the political values that contradict their own $>$, < believe that all policy are either liberal or conservative $>$ although they $<$ have a range of moral intuitions that can be used to analyze ideologies $>$. 
Context

$$
\begin{aligned}
& <\text { Intervention }>\text { for }<\text { learners } \mathrm{A}> \\
& \text { facilitated by }<\text { instructors } \mathrm{B}>\text {, } \\
& \text { includes }<\text { facilities } \mathrm{C}>,<\text { materials } \\
& \mathrm{D}>\text {, < equipment } \mathrm{E}>\text {, < institutions } \mathrm{F}> \\
& \text { and }<\text { organisations } \mathrm{G}>\text { and } \\
& <\text { communities } \mathrm{H}>\text {. }
\end{aligned}
$$

$<$ A student-led network of extra-curricular policy advocacy chapters $>$ for $<$ university students $>$ is facilitated by $<$ peer leaders $>$ includes $<$ university facilities $>$, $<$ an online learning platform $>$, < accessed via studentowned laptops $>$, <partially funded by the university $>$, <receives mentoring and instructional support from network headquarters $>$ and $<$ has mixed support from students' parents $>$.

\section{Design research, engineering, sciences of the artificial}

Design If you want to design an intervention

to promote learning of $<$ task $X>$ to $<$ learners $\mathrm{Y}>$ in $<$ context $\mathrm{Z}>$, then you should give that intervention $<$ substantive characteristics A, B, C > via $<$ process D, E, F>, because of $<$ reasons/principles G, H, I>.
If you want to design an intervention to promote learning of < policy analysis $>$ to $<$ undergraduates $>$ in $<$ an introductory policy analysis course $>$, you should $<$ use a combination of intelligent tutors for teaching policy analysis skills along with a realistic policy problems> because <intelligent tutors can increase learning by providing step-level feedback while real world projects motivate students and promote transfer $>$.

\section{DR precipitates theoretical products from other methods}

The design arguments produced by DR often require other theoretical contributions produced by other methods that do not require designing practical products (for example empirical observations about learner challenges). However, when creating a novel practical product, design researchers often find that the research produced from studies without a design orientation does not necessarily provide the relevant theoretical contributions, so design researchers often need to produce these other contributions to do their work (Figure 8). In fact, the design process (Table 1) is organised to generate these types of contributions (Easterday et al., 2014). In the focus phase, the designer (or other stakeholder) provides some philosophical, political, or economic justification for the project (a potential contribution of ethics). In the understand phase, designers must understand expertise, learning challenges, and context. And of course in the conceive phase, the designer articulates the design argument that is later instantiated by an artifact in the build phase and supported by empirical evidence in the test phase (Easterday et al., 2014).

This is why DR must incorporate other research processes into the process of design - it needs these processes to produce the other theoretical contributions required to generate design arguments. Furthermore, while other kinds of contributions do not strictly require DR (one could simply use the nested research process), in practice it is unlikely that other researchers will ask all the theoretical questions relevant to design if they are not engaged or in collaboration with a DR project (Vanderlinde \& van Braak, 2010). This tight relation between DR and other forms of research blurs the line between DR and other methods.

A further blurring exists in the test phase. Researchers can test an existing design that they did not design using scientific methods without necessarily engaging in DR. Furthermore, it is almost impossible to study learning in a "natural" context in which learners are not affected by existing designed artifacts. So nondesign researchers can evaluate design arguments (explicitly or implicitly) even if not technically engaging in design. 


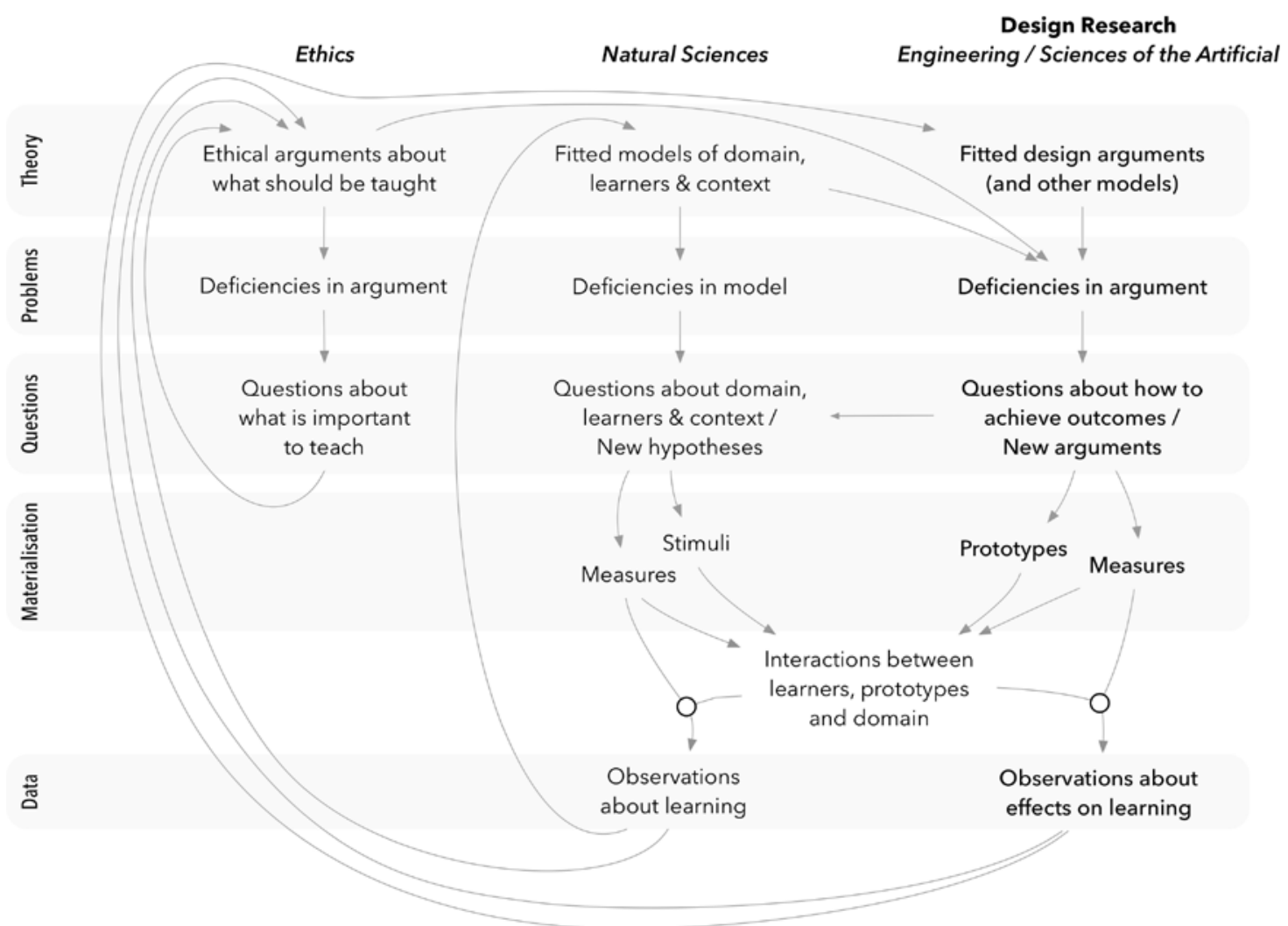

Figure 8. DR is informed by theory from ethics and natural science and precipitates new questions for the natural sciences and ethics.

\section{Conclusion}

To further the paradigmatic development of educational DR, we have defined the products of DR to answer the following questions (Table 3).

Table 3

The definition of design products addresses uncertainties about educational DR

\begin{tabular}{|c|c|c|}
\hline \multicolumn{2}{|c|}{ Question } & Answer \\
\hline 1 & What are DR products for? & $\begin{array}{l}\text { DR products are arguments for how people should learn. } \\
\text { These arguments are made up of practical and theoretical } \\
\text { DR products. }\end{array}$ \\
\hline 2 & $\begin{array}{l}\text { What form do the practical products } \\
\text { of DR take? }\end{array}$ & $\begin{array}{l}\text { The practical products of DR are prototypes that can } \\
\text { promote learning in the real world. }\end{array}$ \\
\hline 3 & $\begin{array}{l}\text { What form do the theoretical } \\
\text { products of DR take? }\end{array}$ & $\begin{array}{l}\text { The theoretical products of DR are design models of how } \\
\text { interventions help people learn, and take the form of } \\
\text { design arguments, blueprints, and mockups, as well as } \\
\text { principles, and frameworks. }\end{array}$ \\
\hline 4 & $\begin{array}{l}\text { How are the theoretical products of } \\
\text { DR related to the theoretical products } \\
\text { in other fields? }\end{array}$ & $\begin{array}{l}\text { DR questions are different from other theoretical } \\
\text { contributions in that they concern the effect of previously } \\
\text { non-existent intervention on learning. Nevertheless, DR } \\
\text { questions cannot be answered without other theoretical } \\
\text { contributions both ethical and scientific (i.e., domain } \\
\text { definition, expertise, learner challenges and context). }\end{array}$ \\
\hline
\end{tabular}

Design models (blueprints, arguments, mockups), as well as principles and frameworks, are theoretical products created by researchers to represent the world, specifically the interaction between people and 
prototypes to achieve learning outcomes. None of these products by itself is "the theory,” rather, they all play a role in the activity of representation. Defining the theoretical products of DR in this way avoids the problematic term of "theory" - theorising is simply the activity of creating these sets of products in an effort to represent the world for different purposes (Giere, 2006, pp. 59-95).

This account resolves the confusion about DR theory raised earlier. First, this account provides a straightforward way to talk about theoretical products of DR in terms of more specific design models (blueprints), more abstract design models (design arguments), as well as principles and frameworks.

Second, this account resolves some of the earlier criticisms of DR theory. The criticism of DR as being overly general and presenting "unfalsifiable propositions, with failures always attributable to defects in implementation rather than flaws in the theory-based design" (Dede, 2004, p. 108) is a result of attending to design principles or arguments that are too abstract, rather than more specific, testable design blueprints. Likewise, grand theories, orienting frameworks, and frameworks for action (diSessa \& Cobb, 2004) describe principles or models that are too abstract. To respond to this criticism, design researchers must provide more specific design models that describe how prototypes are constructed to support interactions with people to promote learning. Design blueprints also overcome the riddle of how researchers can define what is necessary and what is contingent (diSessa \& Cobb, 2004, p. 79) even when generalisable principles do not exist (Giere, 1999). Engineers can describe a design model (such as a blueprint) of a complex design such as a Boeing 747 even if they cannot describe every principle necessary to justify that design (diSessa \& Cobb, 2004, p. 83). Principles can guide the creation of design models, but a design model can still be constructed even in the unfortunate absence of applicable principles.

Third, this account provides more specific guidance to novice design researchers (and even experts!) when responding to criticisms of under-theorised or overly vague theoretical contributions - in either case, the researcher simply has to move up or down in the level of abstraction at which their model is described, while attending to the usual requirement of providing novel additions to existing theory (models).

Defining the logic of the products of DR has implications (beyond the obvious contributions to DR theory). Resolving the theoretical uncertainties advances educational DR towards a high-paradigm field as a result advances the fields of educational research, the learning sciences, and educational technology. This allows us to better train novice researchers, establish reviewing standards that reduce conflicts and uncertainties in publishing work, and increase certainty amongst funders that the resources marshalled for DR projects will result in theoretical and practical benefits for society.

For example, clearer agreement about the standards for DR products and contributions (and especially how they are different from the contributions of other fields) buttresses calls for different publication standards (e.g., Edelson, 2006), such as the longer page limits in educational DR journals needed to describe DR projects, share design blueprints as an important component for publication, include other DR contributions such as proofs of concept with design arguments, and so on. Clearer agreement about the standards for DR allows us to argue for publication of contributions that would otherwise be excluded from journals whose criteria are based on the logic of other methods not developed for the study of complex, iteratively designed interventions.

As another example, clearer agreement about the products of DR (and also its process, discussed in Easterday et al., 2014) provides funders with more certainty about how to evaluate the quality, progress, and likely success of DR proposals. Whereas the methods sections of an exploratory qualitative study or a laboratory experiment describes how data will be collected and analysed, DR proposals must also describe the nature of the intervention designed, such as with blueprints. In addition, DR proposals need to describe the plan for iterative design, development, and formative evaluation. The confusion about the products of DR means that these elements are seldom requirements of DR proposal applications, despite the fact that funders need these elements to judge the likely success of the DR proposal. In this vein, some US National Science Foundation (NSF) programs such as the Cyberlearning program have required applicants to provide an "iterative refinement plan" as part of the proposal. This allows reviewers to judge the agility of the project's process even if specification of the precise measures and instrumentation at the start of the project is not possible. Furthermore, funding agencies such as NSF, with a societal obligation to benefit citizens, are often concerned with the broader impact of research (National Science Foundation, n.d.). Educational 
DR projects move us closer towards producing innovative interventions that directly impact learning than other forms of research. The better able researchers can define these products and impacts, the more confident funding agencies can be that they can achieve their societal mission.

Defining the logic of the products of DR also has implications for more fully realising the promise of useinspired basic research (Stokes, 1997). By articulating the role and importance of practical products in developing theory and achieving broader impacts, we are able to build theory that is more useful in practice and interventions that more effectively help people learn. Understanding the nature and relation of the theoretical and practical products more clearly defines the twin goals of educational DR and how each is indispensable to the other.

Defining the practical and theoretical products of DR furthers the paradigmatic development of DR as a method. This helps us to better train new design researchers; radically increases the confidence of funders as to what they can expect from DR projects and how they might be evaluated; and substantially increases confidence about what counts as a theoretical contribution, improving acceptance rates. Taken together, this allows us, as design researchers, to increase knowledge production of interventions that solve educational problems facing society through the next century.

\section{References}

Alexander, C., Ishikawa, S., \& Silverstein, M. (1977). A pattern language: Towns, buildings, construction. New York, NY: Oxford University Press.

Ambrose, S. A., Bridges, M. W., DiPietro, M., Lovett, M. C., \& Norman, M. K. (2010). How learning works: 7 research-based principles for smart teaching. San Francisco, CA: Jossey-Bass.

Anderson, T., \& Shattuck, J. (2012). Design-based research: A decade of progress in education research? Educational Researcher, 41(1), 16-25. http://dx.doi.org/10.3102/0013189X11428813

Aristotle. (2007). On rhetoric: A theory of civic discourse (G. A. Kennedy, Trans). New York, NY: Oxford University Press. (Original work published ca. 4th century BC)

Arthur, W. B. (2009). The nature of technology: What it is and how it evolves. New York, NY: Free Press.

Ball, D. L., \& Forzani, F. M. (2007). What makes educational research “educational”? Educational Researcher, 36(9), 529-540. http://dx.doi.org/10.3102/0013189X07312896

Bannan, B. (2007). The integrative learning design framework: An illustrated example from the domain of instructional technology. In T. Plomp \& N. Nieveen (Eds.), An introduction to educational design research (pp. 53-73). Enschede: Netherlands Institute for Curriculum Development.

Barab, S., \& Squire, K. (2004). Introduction: Design-based research: Putting a stake in the ground. The Journal of the Learning Sciences, 13(1), 1-14. http://dx.doi.org/10.1207/s15327809jls1301_1

Bitner, M. J., Ostrom, A. L., \& Morgan, F. N. (2008). Service blueprinting: A practical technique for service innovation. California Management Review, 50(3), 66-94. http://dx.doi.org/10.1225/CMR397

Botturi, L. (2006). E2ML: A visual language for the design of instruction. Educational Technology Research and Development, 54(3), 265-293. http://dx.doi.org/10.1007/s11423-006-8807-x

Brown, A. L. (1992). Design experiments: Theoretical and methodological challenges in creating complex interventions in classroom settings. The Journal of the Learning Sciences, 2(2), 141-178. http://dx.doi.org/10.1207/s15327809jls0202_2

Buchanan, R. (2001a). Design and the new rhetoric: Productive arts in the philosophy of culture. Philosophy \& Rhetoric, 34(3), 183-206. http://dx.doi.org/10.1353/par.2001.0012

Buchanan, R. (2001b). Design research and the new learning. Design Issues, 17(4), 3-23. http://dx.doi.org/10.1162/07479360152681056

Collins, A. (1992). Toward a design science of education. In E. Scanlon \& T. O'Shea (Eds.), New directions in educational technology (pp. 15-22). Berlin: Springer. http://dx.doi.org/10.1007/978-3642-77750-9_2

Committee on Facilitating Interdisciplinary Research, \& Committee on Science, Engineering, and Public Policy. (2004). Facilitating interdisciplinary research. Washington, DC: National Academies Press. http://dx.doi.org/10.17226/11153

Dede, C. (2004). If design-based research is the answer, what is the question? A commentary on Collins, Joseph, and Bielaczyc; diSessa and Cobb; and Fishman, Marx, Blumenthal, Krajcik, and Soloway in the JLS special issue on design-based research. The Journal of the Learning Sciences, 13(1), 105-114. http://dx.doi.org/10.1207/s15327809jls1301_5 
diSessa, A. A., \& Cobb, P. (2004). Ontological innovation and the role of theory in design experiments. The Journal of the Learning Sciences, 13(1), 77-103. http://dx.doi.org/10.1207/s15327809jls1301_4

Easterday, M. W., Aleven, V., Scheines, R., \& Carver, S. M. (2011). Using tutors to improve educational games. In G. Biswas, S. Bull, J. Kay, \& A. Mitrovic (Eds.), Artificial intelligence in education: Lecture notes in artificial intelligence 6738 (pp. 63-72). Berlin: Springer.

Easterday, M. W., Rees Lewis, D., \& Gerber, E. M. (2014). Design-based research process: Problems, phases, and applications. In J. L. Polman, E. A. Kyza, D. K. O'Neill, I. Tabak, W. R. Penuel, A. S. Jurow, K. O'Connor, T. Lee, \& L. D'Amico (Eds.), Learning and becoming in practice: The International Conference of the Learning Sciences (ICLS) 2014 (Vol. 1, pp. 317-324). Boulder, CO: International Society of the Learning Sciences.

Edelson, D. (2006). Balancing innovation and risk: Assessing design research proposals. In J. van den Akker, K. Gravemeijer, S. McKenney, \& N. Nieveen (Eds.), Educational design research (pp. 100106). London: Routledge.

Edelson, D. C. (2002). Design research: What we learn when we engage in design. The Journal of the Learning Sciences, 11(1), 105-121. http://dx.doi.org/10.1207/S15327809JLS1101_4

Gamma, E., Helm, R., Johnson, R., \& Vlissides, J. (1995). Design patterns: Elements of reusable objectoriented software. Boston, MA: Addison-Wesley.

Giere, R. N. (1999). Using models to represent reality. In L. Magnani, N. J. Nersessian, \& P. Thagard (Eds.), Model-based reasoning in scientific discovery (pp. 41-57). New York, NY: Springer. http://dx.doi.org/10.1007/978-1-4615-4813-3

Giere, R. N. (2006). Scientific perspectivism. Chicago, IL: University of Chicago Press. http://dx.doi.org/10.7208/chicago/9780226292144.001.0001

Hannon, J., \& Al-Mahmood, R. (2014). The place of theory in educational technology research. In B. Hegarty, J. McDonald, \& S.-K. Loke (Eds.), Rhetoric and reality: Critical perspectives on educational technology: Proceedings of the 31st Annual ASCILITE Conference (pp. 745-750). Dunedin: Australasian Society for Computers in Learning in Tertiary Education. Retrieved from http://www.ascilite.org/conferences/dunedin2014/files/concisepapers/322-Hannon.pdf

Hattie, J. (2009). Visible learning: A synthesis of over 800 meta-analyses relating to achievement. New York, NY: Routledge.

Herrington, J., McKenney, S., Reeves, T., \& Oliver, R. (2007). Design-based research and doctoral students: Guidelines for preparing a dissertation proposal. In C. Montgomerie \& J. Seale (Eds.), Proceedings of World Conference on Educational Multimedia, Hypermedia and Telecommunications 2007 (pp. 4089-4097). Chesapeake, VA: Association for the Advancement of Computing in Education.

Hoadley, C. M. (2004). Methodological alignment in design-based research. Educational Psychologist, 39(4), 203-212. http://dx.doi.org/10.1207/s15326985ep3904_2

Kelly, A. (2004). Design research in education: Yes, but is it methodological? The Journal of the Learning Sciences, 13(1), 115-128. http://dx.doi.org/10.1207/s15327809jls1301_6

Kelly, A. E. (2003). Theme issue: The role of design in educational research. Educational Researcher, 32(1), 3-4. http://dx.doi.org/10.3102/0013189X032001003

Kelly, A. E., Lesh, R. A., \& Baek, J. Y. (2008). Handbook of design research methods in education: Innovations in science, technology, engineering, and mathematics learning and teaching. London: Routledge.

Lee, C. D. (2003). Toward a framework for culturally responsive design in multimedia computer environments: Cultural modeling as a case. Mind, Culture, and Activity, 10(1), 42-61. http://dx.doi.org/10.1207/S15327884MCA1001_05

McKenney, S., \& Reeves, T. C. (2013). Conducting educational design research. London: Routledge.

McKeon, R. P. (1998). Selected writings of Richard Mckeon: Volume one: Philosophy, science, and culture. Chicago, IL: University of Chicago Press.

National Science Foundation. (n.d.). Cyberlearning and future learning technologies (Cyberlearning). Retrieved from http://www.nsf.gov/pubs/2014/nsf14526/nsf14526.htm

Ostrom, E. (2011). Background on the institutional analysis and development framework. Policy Studies Journal, 39(1), 7-27. http://dx.doi.org/10.1111/j.1541-0072.2010.00394.X

Penuel, W. R., \& Fishman, B. J. (2012). Large-scale science education intervention research we can use. Journal of Research in Science Teaching, 49(3), 281-304. http://dx.doi.org/10.1002/tea.21001

Penuel, W. R., Fishman, B. J., Haugan Cheng, B., \& Sabelli, N. (2011). Organizing research and development at the intersection of learning, implementation, and design. Educational Researcher, 40(7), 331-337. http://dx.doi.org/10.3102/0013189X11421826 
Pfeffer, J. (1993). Barriers to the advance of organizational science: Paradigm development as a dependent variable. The Academy of Management Review, 18(4), 599-620. http://dx.doi.org/10.2307/258592

Phillips, R., Kennedy, G., \& McNaught, C. (2012). The role of theory in learning technology evaluation research. Australasian Journal of Educational Technology, 28(7), 1103-1118. http://dx.doi.org/10.14742/ajet.v28i7.791

Plomp, T., \& Nieveen, N. (Eds.). (2007). An introduction to educational design research. Enschede: Netherlands Institute for Curriculum Development.

Rees Lewis, D., Harburg, E., Gerber, E.M., Easterday, M. (2015, June). Building help-seeking tools for novice designers. In Proceedings of the 2015 ACM SIGCHI Conference on Creativity \& Cognition 2015 (pp. 43-52). New York, NY: ACM. http://dx.doi.org/10.1145/2757226.2757248

Reeves, T. C. (2006). Design research from a technology perspective. In J. van den Akker, K. Gravemeijer, S. McKenney, \& N. Nieveen (Eds.), Educational design research (pp. 52-66). London: Routledge.

Sandoval, W. A. (2004). Developing learning theory by refining conjectures embodied in educational designs. Educational Psychologist, 39(4), 213-223. http://dx.doi.org/10.1207/s15326985ep3904_3

Sandoval, W. A. (2014). Conjecture mapping: An approach to systematic educational design research. Journal of the Learning Sciences, 23(1), 18-36. http://dx.doi.org/10.1080/10508406.2013.778204

Schoenfeld, A. H. (2006). Design experiments. In J. L. Green, G. Camilli, \& P. B. Elmore (Eds.), Handbook of complementary methods in educational research (pp. 193-205). Mahwah, NJ: Lawrence Erlbaum.

Shostack, G. L. (1987). Service positioning through structural change. Journal of Marketing, 51(1), 34 43. http://dx.doi.org/10.2307/1251142

Simon, H. A. (1996). The sciences of the artificial (3rd ed.). Cambridge, MA: MIT Press.

Simonsen, J., \& Robertson, T. (Eds.) (2013). Routledge international handbook of participatory design. New York, NY: Routledge. http://dx.doi.org/10.4324/9780203108543

Stokes, D. E. (1997). Pasteur's quadrant: Basic science and technological innovation. Washington, DC: Brookings Institution Press.

Sutherland, J. (2014). Scrum: The art of doing twice the work in half the time. New York, NY: Crown Business.

Tessmer, M., \& Harris, D. (1992). Analysing the instructional setting: Environmental analysis. London: Kogan Page.

The Design-Based Research Collective. (2003). Design-based research: An emerging paradigm for educational inquiry. Educational Researcher, 32(1), 5-8. http://dx.doi.org/10.3102/0013189X032001005

van den Akker, J. (1999). Principles and methods of development research. In J. van den Akker, R. M. Branch, K. Gustafson, N. Nieveen, \& T. Plomp (Eds.), Design approaches and tools in education and training (pp. 1-14). Dordrecht: Kluwer Academic Publishers. http://dx.doi.org/10.1007/978-94-0114255-7

van den Akker, J., Gravemeijer, K., McKenney, S., \& Nieveen, N. (2006). Educational design research. Abingdon: Taylor \& Francis.

Vanderlinde, R., \& van Braak, J. (2010). The gap between educational research and practice: views of teachers, school leaders, intermediaries and researchers. British Educational Research Journal, 36(2), 299-316. http://dx.doi.org/10.1080/01411920902919257

van Merriënboer, J. J. G., \& Kirschner, P. A. (2007). Ten steps to complex learning: A systematic approach to four-component instructional design. Mahwah, NJ: Lawrence Erlbaum Associates.

Zimmerman, J., Forlizzi, J., \& Evenson, S. (2007). Research through design as a method for interaction design research in HCI. In Proceedings of the SIGCHI Conference on Human Factors in Computing Systems (pp. 493-502). New York, NY: ACM. http://dx.doi.org/10.1145/1240624.1240704 


\section{Acknowledgments}

We would like to thank Bruce Sherin, Christina Krist, and Pryce Davis and the anonymous reviewers for their insights and critique of this work, which was supported by the National Science Foundation under Grant No. IIS-1320693, IIS-1217225, and IIS-1530833.

Corresponding author: Matthew W. Easterday, easterday@northwestern.edu

Australasian Journal of Educational Technology (c) 2016.

Please cite as: Easterday, M. W., Rees Lewis, D. G., \& Gerber, E. M. (2016). The logic of the theoretical and practical products of design research. Australasian Journal of Educational Technology, 32(4), 125144. http://dx.doi.org/10.14742/ajet.2464 